\title{
Facilitation of Pavlovian Conditioned Cardiodecelerations Following Preshock in Immobilized Rats
}

\author{
LINDA M. WILSON ${ }^{2}$, J. ROGER WILSON AND LEO V. DICARA \\ Department of Psychiatry, Mental Health Research Institute \\ University of Michigan Medical Center, Ann Arbor, MI
}

(Received 19 February 1975)

\begin{abstract}
WILSON, L. M., J. R. WILSON AND L. V. DICARA. Facilitation of Pavlovian conditioned cardiodecelerations following preshock in immobilized rats. PHYSIOL. BEHAV. 15(6) 653-658, 1975. - Two experiments are reported that examine the effects of unsignalled, inescapable prior shock exposure (PSE) on shock-motivated Pavlovian conditioned heart rate (HR) decelerations in rats. Both studies involved 2 CS-US contingencies (paired and unpaired) and 2 preshock treatments (preshock and no preshock). The 2 designs differed in the type of immobilization procedures to which the rats were submitted and the number of conditioning sessions. In Experiment 1 rats were conditioned for 2 consecutive 35 trial sessions while physically restrained, whereas only one conditioning session was used in Experiment 2 on animals that were paralyzed with d-tubocurarine chloride (dTC). The results demonstrated that PSE augmented the magnitude of the HR conditioned response (CR) in both the physically restrained and paralyzed preparations. In addition, PSE improved the rate of acquisition of the conditioned cardiodeceleration in physically restrained rats and tended to facilitate reinstatement of the HR CR during the second conditioning session. These data support the notion that certain nonspecific stress processes that are relatively independent of the CS-US contingency but related to the occurrence of response suppression are intimately involved in Pavlovian HR conditioning.
\end{abstract}

Pavlovian conditioning Heart rate Preshock Physical restraint Curare

THE notion that similar central processes simultaneously initiate somatic and heart rate (HR) activity $[4,5,16,22]$ suggests that Pavlovian conditioned HR decelerations observed in immobilized rats $[27,28,31,32]$ are linked to mechanisms regulating response inhibition. Crouching or freezing is one form of response inhibition that serves as an unconditioned species-specific defense reaction to shock, as well as an anticipatory reaction to contextual stimuli associated with shock $[6,7,8]$.

Since response suppression is readily conditioned to stimuli associated with shock, and if the assumption is valid that central activities constitute the organization of both HR and behavioral activities, then those circumstances that strengthen the crouching or freezing tendency in the presence of a fear-eliciting stimulus should also facilitate concomitant HR decelerations. For instance, increasing the shock intensity in a Pavlovian fear conditioning situation tends to simultaneously enhance stimulus control over both conditioned HR responses [15] and the crouching tendency, as inferred from the animal's ability to suppress the immobility response $[6,7,11,12]$. Mounting evidence indicates that the immobility reaction can be strengthened during associations developed relatively independently of those formed during the Pavlovian CS-US pairings. For example, unsignalled, inescapable prior shock exposure (PSE) increases a rat's tendency to freeze in the test situation, which subsequently either enhances or impedes its ability to acquire a shock-motivated avoidance response, based on the particular requirements of the task [3] .

Very little is known about the influence of nonspecific stress on basal and conditioned cardiovascular activity [32]. Accordingly, the following experiments were designed to determine if the principles of PSE that apply to strengthening a species-specific defense reaction of response suppression facilitate conditioned $\mathrm{HR}$ decelerations under two conditions of immobilization: physical restraint (Experiment 1) and curare-induced neuromuscular paralysis (Experiment 2).

\section{EXPERIMENT 1}

\section{METHOD}

\section{Animals}

Twenty-four naive adult male Sprague-Dawley rats, purchased from Spartan Research Animals, Inc., Haslett,

${ }^{1}$ This research was supported by Grant No. MH 21403 from the United States Public Health Service, and No. $71-797$ from the American Heart Association to LVD. Portions of this study were presented at the American Psychological Association 82 nd Annual Convention held in New Orleans, La., 1974, by JRW. The authors gratefully acknowledge the technical assistance of Mr. Ronald Derman.

${ }^{2}$ Address reprint requests to: L. M. Wilson, Mental Health Research Institute, University of Michigan, Ann Arbor, MI 48109. 
Michigan, were used. All animals weighed $375-450 \mathrm{~g}$ at the time of testing, had no previous drug experience, and were adapted to the standard laboratory regimen of free access to food and water for at least one week before the initiation of the experiment. All rats were individually housed in wire-mesh cages in a room cycled on a $12 \mathrm{hr}$ light-12 hr dark schedule.

Twenty-four hr before the first day of conditioning the animals were lightly etherized and implanted with subcutaneous EKG electrodes. The electrodes consisted of 2 stainless steel coils inserted between the scapula and on the base of the tail.

\section{Apparatus}

All rats were enclosed in a $180 \times 60 \times 38 \mathrm{~cm}$ (BRS Foringer) acoustic chamber, completely insulated with copper mesh, during adaptation and training. The stimulus display (a Mallory Sonalert adjacent to a faceted indicator lamp) was mounted $10 \mathrm{~cm}$ in front of the animal $8 \mathrm{~cm}$ above the chamber floor. The conditional stimulus (CS) consisted of a $5 \mathrm{sec}$ presentation of a $1 \mathrm{KHz} 78 \mathrm{~dB}$ (SPL) tone and a $5 \mathrm{~W}$ light. The $\mathrm{CS}$ was presented against a background of a $72 \mathrm{~dB}$ noise generated by the housing ventilation fan and terminated with a $450 \mathrm{msec} 1.2 \mathrm{~mA}$ tail shock (US). The US was similar to that described by Wilson and DiCara [32]. Briefly it was of a series resistance variety that offered a relatively constant $60 \mathrm{~Hz} \mathrm{AC}$ current. External relay switching controlled the line voltage at the primary of a 6:1 step-up transformer. The secondary was connected to the tail electrode through a voltage divider network employing a $200 \mathrm{~K} \Omega$ variable calibration resistor, a $200 \mathrm{~K} \Omega$ ten turn potentiometer, and a $300 \mathrm{~K} \Omega$ output resistor. High voltage switching transients were eliminated by placing a capacitor in parallel with the shock output. The only housing illumination was provided by the CS presentations. All trials were programmed with BRS Foringer solid-state logic according to an intertrial interval (ITI) averaging $100 \mathrm{sec}$ with a range of $20-180 \mathrm{sec}$.

\section{Procedure}

On the first conditioning day rats were lightly etherized to minimize struggling and then physically restrained as in the procedure described by Holdstock and Schwartzbaum [18]. Briefly, the rats were positioned on a $27 \times 8 \mathrm{~cm}$ Plexiglas cradle consisting of two sets of apertures, or guideholes, for inserting the limbs. The rat's forelimbs were gently drawn through the anterior guideholes and securely bound to the anchor support beneath the restraining cradle with surgical adhesive tape. The animal's hindlimbs were drawn through the posterior apertures and similarly secured. A $5 \mathrm{~cm}$ wide strip of Velcro was then snugly wrapped around the animal's midthoracic region and secured under the cradle platform. Head movements were prevented by a piece of adhesive bandage tied over and across the neck and under the cradle, while an additional bandage minimized movement of the hindquarters. In general, this procedure was very effective in preventing vertical or lateral body displacements that could interfere with acceptable EKG recordings.

The restrained animal was then placed into the test chamber. A tail shock electrode described by Weiss [29] was then sparingly coated with electrode paste to maintain optimal electrical contact and fastened around the base of the rat's tail. The EKG leads were attached to the implanted coils, the chamber door was closed, and the animal was permitted a $30 \mathrm{~min}$ adaptation period before conditioning started. Following adaptation the animals were randomly assigned to 1 of 2 pretraining groups:

(1) Preshock group (PS). These rats were presented a series of $201 \mathrm{sec}, 1.2 \mathrm{~mA}$ RMS tail shocks distributed on a VI $60 \mathrm{sec}$ schedule. All shocks were unsignalled and inescapable.

(2) No Preshock group (NPS). These animals received an additional $20 \mathrm{~min} 20 \mathrm{sec}$ in the conditioning apparatus prior to the onset of training. This interval corresponded to the time required to deliver the 20 tail shocks to the PS group.

Following this pretraining period, animals were assigned to 1 of 2 conditioning groups:

(1) Paired CS-US group (P). Animals in this group received 35 classical conditioning trials in which a $5 \mathrm{sec} C S$ (tone plus light) terminated with the onset of a $450 \mathrm{msec}$ $1.2 \mathrm{~mA}$ RMS tail shock. The trials were programmed to occur on a VI $100 \mathrm{sec}$ schedule.

(2) Unpaired CS and US control group (UP). Animals in this group received 35 presentations of the $5 \mathrm{sec} C S$ and of the 450 msec US. However, CSs were presented, on the average, every $100 \mathrm{sec}$; USs were programmed to occur randomly within the $100 \mathrm{sec}$ ITI. This group was included to determine if preshock was primarily affecting the CS-US bond or was merely producing sensitization to the US.

Following this training session the rats were returned to their home cages. The same conditioning procedure was followed the next day, except that the pretraining manipulation was omitted.

\section{Data Analysis}

A Grass Model 7B polygraph was used to record the EKG. The signals were led into a Grass preamplifier (Model 7P5-A) and driver amplifier. For each of the 35 daily trials, the rat's HR was sampled for $5 \mathrm{sec}$ prior to $\mathrm{CS}$ onset, and during the $5 \mathrm{sec}$ CS presentation. Heart rate measurements were determined by manually counting the number of heart beats that occurred during these intervals. The conditioned response (CR) was defined as the CS HR minus the preCS HR. The preCS score served as the basal heart rate estimate. All heart rate scores were converted to beats per min (BPM) for statistical analysis. Because of occasional shock artifact contaminating the records of postUS HR, the decision was made to omit the unconditioned response (UR) data from the statistical analysis.

\section{RESULTS AND DISCUSSION}

A $2 \times 2 \times 2 \times 6$ (Preshock $\times$ Contingency $\times$ Days $x$ Trial Blocks) repeated measures analysis of variance was conducted on the CS-preCS HR difference scores and on the preCS basal HR estimates. The first five-trial block was omitted from the ANOVA in the first experiment. The first five-trial block was omitted from the ANOVA in the first experiment. This block was considered as a test adaptation for the physically restrained rats. Multiple comparisons following an overall significant $\mathrm{F}$ value were made with $t$ tests.

Figure 1 illustrates that preshocked rats (PS) displayed augmented HR decelerations to the CS compared to their nonshocked controls (NPS), $F(1,20)=13.71, p<0.005$. In 


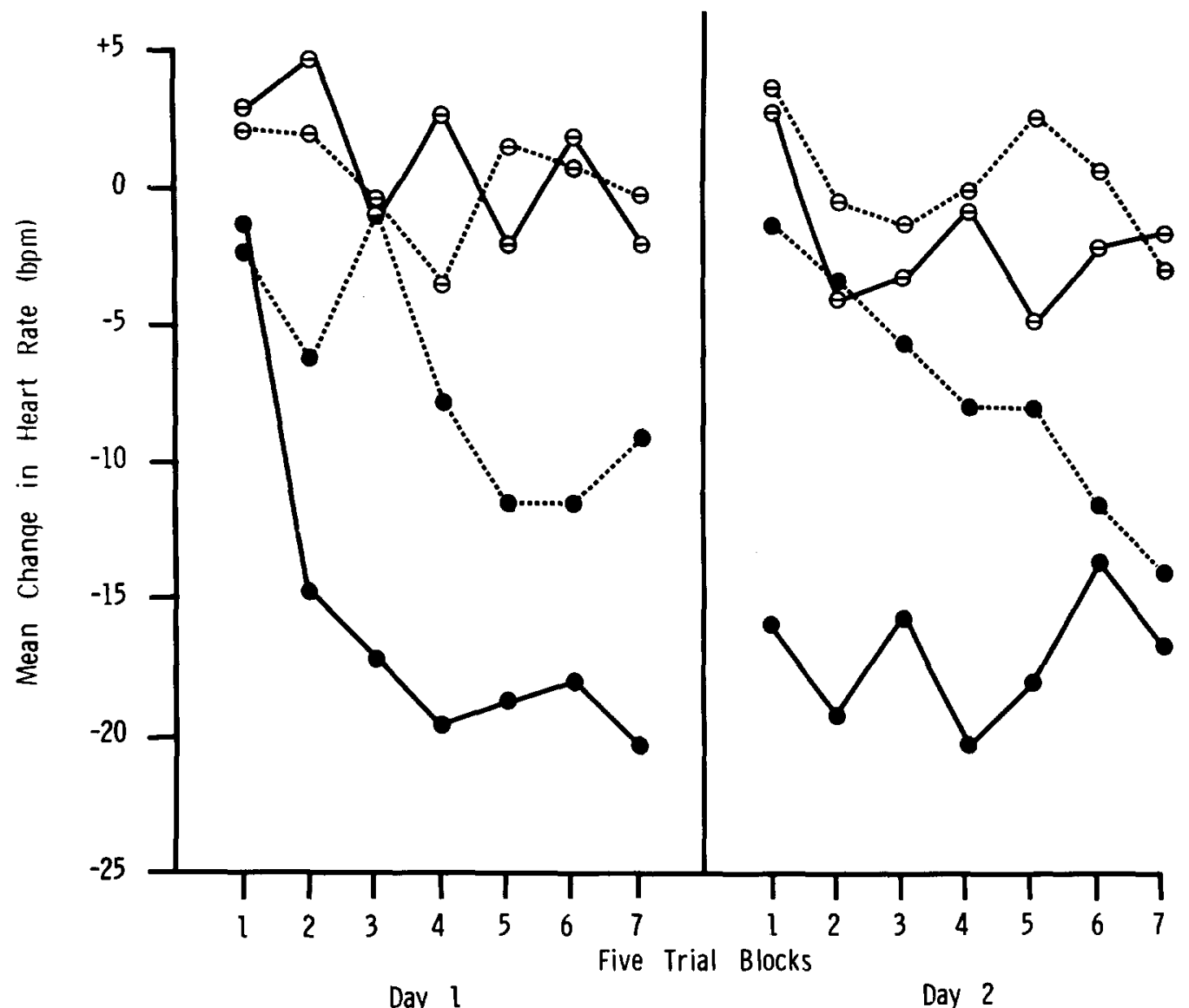

FIG. 1. Mean CS-PreCS heart rate in beats per min (BPM) for each physically restrained group as a function of 5-trial blocks during 2 days of Pavlovian conditioning. $-\bullet$, PPS; $\bullet-. \bullet$ PNPS; $\ominus-\ominus$, UPPS; $\odot-.-0$, UPNPS. (Abbreviations: PPS = Paired Preshock; PNPS = Paired No Preshock; UPPS = Unpaired Preshock; UPNPS = Unpaired No Preshock.)

addition, animals exposed to paired CS-US presentations consistently decelerated to the CS $(P)$, while those rats in the UP groups showed no systematic response, $F(1,20)=$ $74.11, p<0.01$. The preshock manipulation was particularly effective when it preceded paired CS-US presentations (Preshock $\times$ Contingency interaction: $F(1,20)=10.28$, $p<0.005$. Although all 4 groups showed no systematic HR response to the CS on the first block of training trials, P-PS rats exhibited a rapid acquisition of decelerative HR CRs across blocks. Furthermore, the HR CRs for these animals asymptoted sooner and at a lower level than those for the P-NPS, UP-PS, or the UP-NPS groups. It is unlikely that the preshock effects were primarily due to shock sensitization, since UP-PS rats, who received identical pretraining treatment to P-PS rats, showed no conditioning across blocks or days of training. In addition, although preshock experience preceded only the Day 1 training session, Fig. 1 clearly shows that the augmented conditioned cardiodecelerations for the P-PS rats were retained from Day 1 to Day 2. The P-NPS rats began the second session with mean cardiodecelerations similar to those of Day $1(p>0.05)$, before they successively decreased across trial blocks.

Animals in the paired CS-US groups not experiencing preshock demonstrated little evidence of conditioning until the later acquisition trials. Figure 1 reveals that early in training P-NPS rats did not differ from their unpaired controls (UP-NPS) in their HR response to the CS $(p>0.05)$.

A $2 \times 2 \times 2 \times 6$ ANOVA of the mean basal HRs (preCS values) for all treatment groups throughout training showed no main effects for either Preshock or Contingency. Therefore, although all preshocked rats experienced more total shock than nonpreshocked controls, baseline HRs did not differ significantly between the two groups. However, basal HR generally decreased between Day 1 and Day 2 of conditioning, $F(1,20)=17.02, p<0.001$, while a slight increase in HR occurred within sessions, $F(5,100)=7.96$, $p<0.01$.

The absence of preCS differences suggests that the nonspecific stress experienced during immobilization may have precluded any systematic PSE effects on basal HR. However, the general elevation in basal HR levels that did occur across trials within the sessions is consistent with other reports of preCS shifts in HR during Pavlovian conditioning in the immobilized rat $[17,18,24,25,32]$.

\section{EXPERIMENT 2}

The difficulty experienced in obtaining stable HR conditioning in curarized animals has often been viewed as a consequence of inadequate respiration or the vagolytic properties of the neuromuscular blocker [19]. However, 
there is a strong indication that the disrupting influences exhibited in the curarized preparation can also be observed in the nonparalyzed, physically restrained rat. For instance, Wilson and DiCara [32] suggested that adaptation to immobilization-induced nonspecific stress facilitates Pavlovian conditioned HR decelerations in both physically restrained and paralyzed rats. Thus, one disruptive feature of stress appears to be common to both immobilization procedures. If other basic features are similar, then strengthening the mediational processes underlying response suppression could facilitate HR conditioning in curare-immobilized rats. Accordingly, the following study used the PSE procedure on rats paralyzed with d-tubocurarine chloride (dTC).

\section{METHOD}

\section{Animals and Procedure}

Selection, purchase, and maintenance of the animals were similar to Experiment 1. The design was also similar to the previous experiment except that in this case the rats were lightly etherized and then curarized, instead of physically restrained. The injection procedure was similar to that previously used by Wilson and DiCara [32]. This involved a single intraperitoneal injection of d-tubocurarine chloride (dTC) $(2.5 \mathrm{mg} / \mathrm{kg}$ body weight) in a $3.0 \mathrm{mg} / \mathrm{cc}$ solution (Squibb) following etherization. When the rat showed signs of respiratory distress it was placed into a face mask modified from a rubber balloon [13]. The balloon was positioned behind the upper incisors and pulled tightly over the rat's snout. The balloon was attached to a rubber stopper which held a Y-tube connected by polyethylene tubing to the inspirator and expirator tube on a small animal respirator (Harvard 680). The rats were respirated at a $1: 1 \mathrm{l} / \mathrm{E}$ ratio at approximately $68-72 \mathrm{cpm}$ with a $6 \mathrm{cc}$ positive pressure vol/stroke. During paralysis the rats lay on folded surgical padding and were respirated until they regained sufficient motor control to sustain respiration without aid.

The conditioning procedure was administered in one 35 trial session. The animals were randomly assigned to 1 of 4 experimental groups $(\mathrm{N}=8$ per group):

(1) a curarized paired preshock group (C-PP), in which curarized rats received 35 CS-US pairings, following a series of unavoidable and inescapable tail shocks, similar to the procedures described for P-PS rats in Experiment 1.

(2) a curarized paired no preshock group (C-PNP), in which rats were trained like P-NPS rats in Experiment 1 without any preconditioning aversive stimulation.

(3) a curarized unpaired preshock group (C-UPP).

(4) a curarized unpaired no preshock group (C-UPNP).

The latter groups were given 35 independent presentations of the CS and the US, either following pretraining shock exposure or a similar period in which they were left undisturbed.

All animals were allowed a $30 \mathrm{~min}$ curare stabilization period following dTC injection before the pretraining period began. The CS complex, as well as its location relative to the animal's position, was similar to that described in the first experiment. Although electromyographic activity was not monitored, examination of the status of recovery from paralysis after conditioning as well as observations from previous studies [32,33] strongly indicated that the results described below cannot be attributed to a differential reinstatement of skeletal motor control.

\section{RESULTS}

Figure 2 shows the mean change in HR during CS presentations across the 7 five-trial blocks on the first day of training for the 4 treatment groups. The $2 \times 2 \times 7$ (Preshock $\times$ Contingency $\times$ Trial Blocks) repeated measures analysis revealed that, at least on the first day of conditioning, prior shock exposure significantly augmented the magnitude of the cardiodecelerations to the CS, F $(1,28)$ $=5.74, p<0.05$. Furthermore, the preshock-induced increase in the magnitude of the cardiodeceleration occurred only in those animals also experiencing paired CS-US presentations (viz., C-PP rats) (Preshock $\times$ Contingency interaction: $F(1,28)=4.66, p<0.05$. Group comparisons $(t$ tests) demonstrated C-PP rats showed greater conditioned cardiodecelerations than either their sensitization controls (C-UPP) or the C-PNP rats $(p<0.05)$. No significant differences were found between C-PNP and their C-UPNP controls.

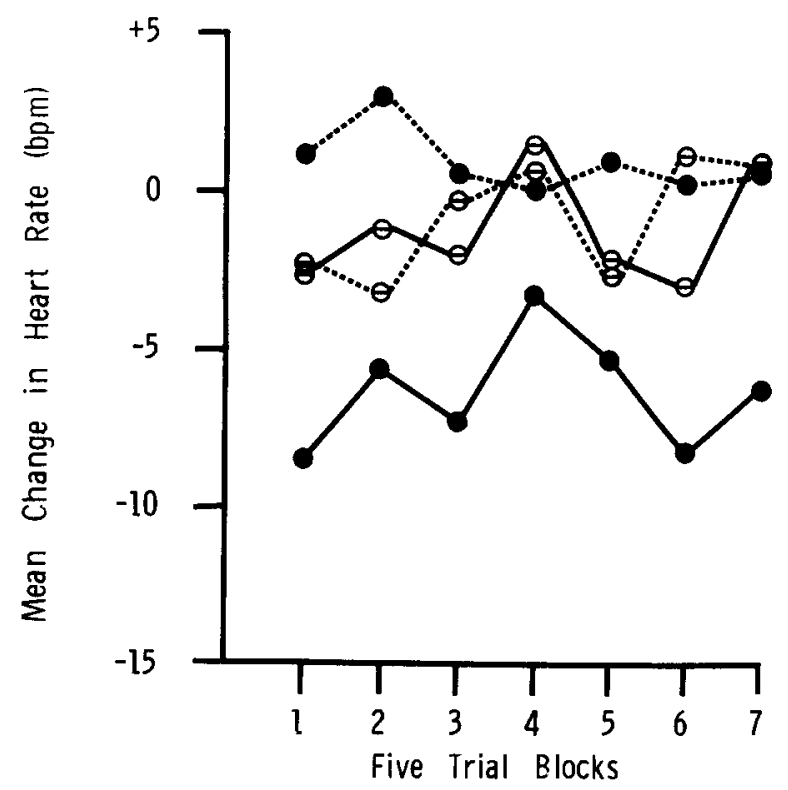

FIG. 2. Mean CS-PreCS heart rate in beats per min (BPM) for each dTC-immobilized group as a function of 5-trial blocks of trials recorded during a single 35 trial conditioning session. $\longrightarrow, \mathrm{C}$-PP;

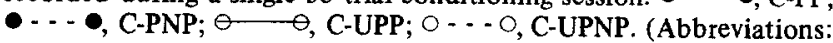
C-PP $=$ Curarized - Paired Preshock; C-PNP = Curarized - Paired No Preshock; C-UPP = Curarized - Unpaired Preshock; C-UPNP = Curarized - Unpaired No Preshock.)

Basal HRs were not dependent on either prior shock exposure or contingency factors. However, as in the first experiment, HRs displayed a reliable tendency to increase across trial blocks in training, $F(6,168)=3.29, p<0.005$. On the average, basal $H R$ in the curarized preparation remained in the 430-440 BPM range. These values were 10-20 BPM slower than the mean basal HRs on the first day of training for the physically restrained animals in Experiment 1, which ranged between 440-460 BPM.

A comparison of Fig. 1 and 2 revealed that the mean HR CR's for physically-restrained rats who received paired 
CS-US presentations in training were augmented by 5-10 BPM over those of the curarized-paired groups. According to a law of initial values [30], the higher basal HRs of the physically-immobilized rats provide partial explanation for the enhanced cardiodecelerations of this group. Additionally, documented vagolytic properties of dTC [19] may restrict the potential magnitude of the vagally-mediated CR in the curarized rats to a smaller range than in their noncurarized counterparts.

\section{DISCUSSION}

The fact that Pavlovian HR conditioning is strengthened under apparently elevated (PSE) or attenuated [32] stress conditions presents somewhat of a paradox. Since HR CRs are predominantly vagally mediated $[10,14]$, a cardiacsomatic coupling implies that increases in vagal tone are generally supported by a suppression of skeletal-motor activity. Thus, it might be anticipated that the $C R$ amplitude can be disrupted under conditions that either favor sympathetic antagonism of this vagal response, or elicit incompatible skeletal activity. Although little is known of the sympatho-adrenal contributions to conditioned cardiovascular activity, several investigators [23] have emphasized that acute stress strengthens sympathetic competition. If immobilization induces nonspecific stress, it may elicit sympatho-adrenal activation as well as struggling, and other escape behaviors in the physically restrained animal inconsistent with conditioned cardiodecelerations. The facilitation of Pavlovian HR conditioning by immobilization adaptation [32] might be interpreted as indicating that minimizing these conflicting tendencies strengthens stimulus control over the vagal response. Moreover, the results of the present study indirectly suggest that PSE, like immobilization adaptation, strengthens the occurrence of response inhibition (i.e., a decrease in somatic activity) during subsequent Pavlovian conditioning trials which may counter those tendencies usually dominant during immobilization-induced stress. Recent studies on the effects of PSE on the acquisition of an instrumental avoidance response support this contention. Anisman [2] found that preshock administered to either physically restrained or anectinized rats significantly lowered basal activity in the training situation and, thereby, retarded avoidance acquisition.
The characteristics of the stimulus-induced HR response in the physically restrained rat are consistent with previous studies $[8,24,25]$. The finding that HR CRs approached the magnitude of those reported by Holdstock and Schwartzbaum [18] only on the second consecutive day of conditioning confirm Wilson and DiCara's [32] assertion that habituation of immobilization-induced nonspecific stress may be a critical methodological requisite for rapid HR conditioning in the restrained rat. One additional feature of conditioning was also noted in this preparation: Even though the PSE experience was omitted on the second day, it facilitated both acquisition and retention across the two consecutive days of conditioning. In this connection, Anderson et al. [1] observed improved retention of passive avoidance performance following PSE. The inability to produce HR CRs in the nonpreshocked animals in Experiment 2 supports earlier reports of invariant HRs in nonhabituated, curare-immobilized rats $[19,20,32]$. However, the fact that PSE produced stable Pavlovian conditioned HR decelerations is consistent with Wilson and DiCara's [32] observation that certain difficulties experienced with the curarized preparation are not attributable to the pharmacological consequences of neuromuscular paralysis or artificial respiration.

In addition to the absence of conditioning following unpaired presentations of the CS and US, previous studies render the possibility that alterations in shock aversion thresholds or sensory preconditioning influenced the CR very remote. For instance, Brookshire, et al. [9] and Anderson et al. [1] reported that preshock produced, if anything, elevations in psychophysically determined aversiveness thresholds. Moreover, Rescorla [26] recently demonstrated that the information the animal retains about the US following preshock does not affect responding to a neutral CS. Thus, conceptually, it appears that strong mediational drive stimuli are established during PSE which facilitate the transfer of shock-produced cues to the conditioning situation. Procedurally, though, the most conducive circumstances for demonstrating Pavlovian conditioned HR decelerations apparently occur when the animals are stress adapted or when the prepotent skeletalmotor response to the fear stimulus (e.g., freezing) is compatible with the cardiodecelerations.

\section{REFERENCES}

1. Anderson, D. C., J. Cole and W. McVaugh. Variations in unsignalled inescapable preshock as determinants of responses to punishment. J. comp. physiol. Psychol. 65: (Monogr. Suppl. No. 3), 1968.

2. Anisman, H. Effects of response restriction during exposure to inescapable shock upon subsequent one-way and shuttleavoidance performance in rats. Can. J. Psychol. 27: 280-291, 1973.

3. Anisman, H. and T. G. Waller. Effects of inescapable shock on subsequent avoidance performance: Role of response repertoire changes. Behav. Biol. 9: 331-355, 1973.

4. Black, A. H. Autonomic aversive conditioning in infrahuman subjects. In: Aversive Conditioning and Learning, edited by F. R. Brush. New York: Academic Press, 1971, pp. 3-104.

5. Black, A. H. and L. de Toledo. The relationship among classically conditioned responses: Heart rate and skeletal behavior. In: Classical Conditioning II: Current Theory and Research, edited by A. H. Black and W. F. Prokasy. New York: Appleton-Century-Crofts, 1972, pp. 290-311.
6. Blanchard, R. J. and D. C. Blanchard. Crouching as an index of fear. J. comp. physiol. Psychol. 67: 370-375, 1969.

7. Bolles, R. C. Species-specific defense reactions and avoidance learning. Psychol. Rev. 77: 32-48, 1970.

8. Bolles, R. C. and S. A. Moot. Response repertoire changes to signalled and unsignalled shock. Paper presented at the Tenth Annual Meeting of the Psychonomic Society, San Antonio, November, 1970.

9. Brookshire, K. H., R. A. Littman and C. N. Stewart. Residua of shock trauma in the white rat: A three factor theory. Psychol. Monogr. 75: (Whole No. 514), 1961.

10. Cohen, D. H. Analysis of the final common path for heart rate conditioning. In: Cardiovascular Psychophysiology: Current Issues in Response Mechanisms, Biofeedback, and Methodolo gy, edited by P. A. Obrist, A. H. Black, J. Brener and L. V. DiCara. Chicago: Aldine, 1974, pp. 117-135.

11. de Toledo, L. and A. H. Black. Heart rate: Changes during conditioned suppression in rats. Science 152: 1404-1406, 1966. 
12. de Toledo, L. and A. H. Black. Effects of preshock on subsequent avoidance conditioning. J. comp. physiol. Psychol. 63: 493-499, 1967

13. DiCara, L. V. Analysis of systemic arterial blood gases in the artificially respirated curarized rat. Behav. Res. Meth. Instrum. 2: $67-69,1970$.

14. Fitzgerald, R. D., G. K. Martin and J. H. O'Brien. Influence of vagal activity on classically conditioned heart rate in rats. $J$. comp. physiol. Psychol. 83: 485-491, 1973.

15. Fitzgerald, R. D. and T. J. Teyler. Trace and delayed heart rate conditioning in rats as a function of US intensity. J. comp. physiol. Psychol. 70: 242-253, 1970.

16. Germana, J. Central efferent processes and autonomic-behavioral integration. Psychophysiology 6: 78-90, 1969.

17. Hahn, W. W. and J. Slaughter. Heart rate responses of the cu rarized rat. Psychophysiology 7: 429-435, 1970.

18. Holdstock, T. and J. Schwartzbaum. Classical conditioning of heart rate and GSR in the rat. Psychophysiology 2: 25-38, 1965.

19. Howard, J. L., R. A. Galosy, C. J. Gaebelein and P. A. Obrist Some problems in the use of neuromuscular blockade. In Cardiovascular Psychophysiology: Current Issues in Response Mechanisms, Biofeedback, and Methodology, edited by P. A. Obrist, A. H. Black, J. Brener and L. V. DiCara. Chicago: Aldine, 1974, pp. 353-361.

20. Miller, N. E. and B. R. Dworkin. Visceral learning: Recent difficulties with curarized rats and significant problems for human research. In: Cardiovascular Psychophysiology: Current Issues in Response Mechanisms, Biofeedback, and Methodology, edited by P. A. Obrist, A. H. Black, J. Brener, and L. V. DiCara. Chicago: Aldine, 1974, pp. 312-331.

21. Myer, J.S. Some effects of noncontingent aversive stimulation. In: Aversive Conditioning and Learning, edited by F. R. Brush. New York: Academic, 1971, pp. 469-536.

22. Obrist, P. A., J. L. Howard, J. E. Lawler, R. A. Galosy, K. A. Meyers and C. J. Gaebelein. The cardiac-somatic interaction. In: Cardiovascular Psychophysiology: Current Issues in Response Mechanisms, Biofeedback, and Methodology, edited by P. A. Obrist, A. H. Black, J. Brener, and L. V. DiCara. Chicago: Aldine, 1974, pp. 136-172.
23. Obrist, P. A., J. E. Lawler, J. L. Howard, K. W. Smithson, P. L. Martin and J. Manning. Sympathetic influences on cardiac rate and contractility during acute stress in humans. Psychophysiol. ogy 11: 405-427, 1974.

24. Ray, R. Classical conditioning of heart rate in restrained and curarized rats. Unpublished dissertation, University of Tennessee, 1969.

25. Ray, R. Use of the conditional reflex to assess the temporal characteristics of curarization effects on heart rate responding. Cond. Reflex 7: 19-32, 1972.

26. Rescorla, R. A. Effect of inflation of the unconditioned stimulus value following conditioning. J. comp. physiol. Psychol. 86: $101-106,1974$.

27. Teyler, T. J. Effects of restraint on heart rate conditioning in rats as a function of US location. J. comp. physiol. Psychol. 77: 31-37, 1971 .

28. Vardaris, R. M. Partial reinforcement and extinction of heart rate decelerations in rats with the US interpolated on nonreinforcement trials. Learn. Motiv. 2: 280-288, 1971

29. Weiss, J. M. A tail electrode for unrestrained rats. J. exp. Analysis Behav. 10: 85-86, 1967.

30. Wilder, J. The law of initial values in neurology and psychiatry: Facts and problems. J. nerv. ment. Dis. 125: 73-86, 1957.

31. Wilson, J. R. Stress variables involved in Pavlovian heart rate conditioning in the curarized rat. In: Visceral learning in curarized animals. J. L. Howard (Chair). Symposium presented at the 82nd Annual Convention of the American Psychological Association, New Orleans, La., 1974.

32. Wilson, J. R. and L. V. DiCara. Effects of previous curareimmobilization in Pavlovian conditioned heart decelerations in the curarized rat. Physiol. Behav. 14: 259-264, 1975.

33. Wilson, J. R. and L. V. DiCara. Influence of neuromuscular blocking drugs on recovery of skeletal electromyographic activity in the rat. Psychophysiology 12: 249-253, 1975. 